\title{
А.Л. СмышЛЯЕВ
}

\section{ПОНЯТИЯ РИМСКОГО ПРАВА И НАУЧНОЙ ЭТИКИ В РАБОТЕ Д.О. ТУЗОВА ПИСЬМО В РЕДАКЦИЮ}

Поскольку я принимал участие в подготовке русского перевода Дигест Юстиниана, большая критическая рецензия на это издание сразу же привлекла мое внимание. Знакомство с работой Д.О. Тузова вызвало у меня не только удивление, но даже и некоторую оторопь.

Прежде всего, меня поразило, что одна и та же работа была под разными названиями напечатана в двух журналах ${ }^{1}$. Российские исследователи иногда публикуют вышедшие у себя на родине статьи в зарубежных журналах в переводе на один из европейских языков, чтобы познакомить иноязычную научную общественность со своими идеями. Однако здесь совсем другая ситуация - в обоих случаях работа Д.О. Тузова опубликована на русском языке. Интересно, знали ли редакторы польского журнала, принимая в печать эту работу, что она одновременно сдана автором в журнал российский?

${ }^{1}$ Д.О. Тузов, Категории римского права в русском издании Дигест Юстиниана, «Журнал российского права» 2007 № 6(126), с. 117-131; D. Tuzov, Понятия и терминология римского права в русском издании Дигест Юстиниана, «Zeszyty Prawnicze [UKSW]» 7.2 (2007), с. 263-295. Русский вариант чуть короче польского главным образом из-за того, что цитаты из Дигест Юстиниана в нем даются без параллельного латинского текста, но в остальном - это одна и та же работа. 
Кроме того, мне показалось очень странным, что рецензию на русский перевод Дигест Юстиниана написал один из переводчиков. Ведь таким образом он в какой-то мере дает оценку и своей собственной работе, что в науке делать не принято. Еще Макс Вебер отметил, что исследователь должен быть внеположен по отношению к предмету своего исследования.

Удивительно также, что в рецензии на русский перевод Дигест Юстиниана отсутствует общая оценка самого этого перевода. Рецензент с сожалением отмечает отсутствие «у отдельных переводчиков (большинство из которых не юристы, а историки - А.С.) иногда даже самых общих представлений о соответствующих понятиях римского права и об используемых римскими юристами для их обозначения юридических терминах» (с. 265)2. Этот тезис он иллюстрирует примерами из переводов, выполненных ответственным редактором русского издания Дигест Юстиниана Л.Л. Кофановым. С другой стороны, он констатирует, что «в коллектив переводчиков и редакторов Дигест вошел, в том числе, ряд историков, получивших регулярное юридическое образование» и отличающихся «высоким качеством своей работы» (с. 294-295). Поскольку читателю неизвестно соотношение юридически грамотных и неграмотных историков, принимавших участие в переводе Дигест Юстиниана на русский язык, ему остается только гадать, какие же из них преобладают, и насколько в целом хорош или плох русский перевод. Чтобы внести ясность, должен отметить, что из 19 историков и 5 филологов-классиков, участвовавших в переводе Дигест Юстиниана, только двое получили «регулярное юридическое образование», то есть закончили наряду с историческим также и юридический факультет университета. Даже если добавить к ним двух «чистых» юристов, то есть покойного И.С. Перетерского и самого Д.О. Тузова ${ }^{3}$, то впечатление все

2 Здесь и далее все сноски на работу Д.О. Тузова даются по польскому изданию.

${ }^{3}$ Вряд ли образованным читателям юридических журналов надо объяснять, что почти полное отсутствие юристов среди переводчиков русского издания 
равно остается удручающим. Если руководствоваться критериями Д.О. Тузова, то приходится признать, что русский перевод Дигест выполнен в основном полуграмотными дилетантами и, следовательно, никуда не годится.

Д.О. Тузов не случайно избегает общих выводов, ограничиваясь одними намеками. Ведь в его работе отсутствует анализ достоинств и недостатков русского перевода Дигест Юстиниана, как такового. Весь его труд, за исключением нескольких общих фраз в самом начале и в конце, посвящен подробнейшему разбору недостатков и ошибок одного единственного переводчика и по совместительству ответственного редактора этого перевода Л.Л. Кофанова. И вот здесь то и начинается самое удивительное.

Оказывается, хорошо известный российской и польской научной общественности ученый, автор двух монографий и множества статей по римскому праву и истории древнего Рима, а также научных переводов с латинского и древнегреческого языков, не знаком с самыми азами русского языка и латыни, не владеет юридической терминологией, да и вообще отличается элементарным незнанием права. К тому же и в качестве ответственного редактора он проявляет полную несостоятельность и более того без согласия и ведома переводчиков он «исправляет» правильные переводы, искажая их до неузнаваемости. Интересно, что подлинное лицо этого матерого невежды и деспота открыл потрясенной научной общественности сравнительно молодой ученый в своей первой работе по римскому праву. Поневоле вспоминается известная сказка Андерсена.

Однако как ни тяжело отнестись всерьез к работе, в которой совершаются такие «открытия», тем не менее, это необходимо. Ведь многие высказанные Д.О. Тузовым конкретные обвинения, на первый взгляд, выглядят убедительно, иначе два солидных научных журнала не приняли бы ее в печать ${ }^{4}$. Важно разобраться в том, как

Дигест Юстиниана вызвано не чьей-то злой волей, а особенностями истории России в XX веке.

${ }^{4}$ Они бы казались еще более убедительными, если бы не прорывающиеся в работе Д.О. Тузова раздражение и озлобленность, постоянно встречающиеся там 
под видом научной полемики происходит шельмование оппонента, чтобы впоследствии не путать два совершенно разных жанра.

Итак, чтобы опорочить своего оппонента, мало просто указать на допущенные им ошибки. Ведь еще со времен древнего Рима хорошо известно, что «errare humanum est». К тому же, как это справедливо отмечает и сам Д.О. Тузов, даже самым выдающимся ученым не удавалось избежать ошибок и неточностей в переводах латинских юридических текстов, вследствие сложности их грамматической структуры и стилистики (с. 264). Поэтому он постоянно подчеркивает, что Л.Л. Кофанову свойственны грубые элементарные ошибки, убедительно свидетельствующие о его невежестве. Но так ли элементарны указанные Д.О. Тузовым ошибки и всегда ли элементарные ошибки свидетельствуют о невежестве того, кто их совершил? Начнем с «грубых ошибок» при переводе того или иного фрагмента Дигест, а затем обратимся к «элементарным ошибкам», связанным с юридической терминологией.

Разберем первый же пример неверного перевода, приведенный Д.О. Тузовым - Ulp. 13 ad ed. D. 4,1,6:

Proinde et si minor in servitutem redigatur vel ancilla fiat, dominis eorum dabitur non ultra tempus statutum in integrum restitutio. Sed et si forte hic minor erat captus in hereditate quam adierit, Iulianus libro septimo decimo digestorum scribit abstinendi facultatem dominum posse habere...
Соответственно, если лицо, не достигшее 25 лет, отдается в рабство или становится служанкой, то их господину дается восстановление в первоначальном положении в пределах установленного срока. Но и если, возможно, этот несовершеннолетний был обманут в отношении наследства, которое принял, Юлиан в 17-й книге ди-

оскорбительные, не принятые в научной полемике выражения. Недаром, великие римские юристы предупреждали, что «не следует снисходить к злобе» (Cels. 3 dig. D. 6,1,38). 
гест пишет, что господин может получить возможность отказаться (от принятия наследства)...5

Вторая часть этого фрагмента («лицо... было взято в полученном (господином) наследстве»), действительно, переведена Л.Л. Кофановым неверно. Он, по мнению, Д.О. Тузова не знал, что «erat captus...» можно перевести как «был обманут...» и, следовательно, допустил элементарную ошибку (с. 266). Однако Л.Л. Кофанов в той же самой четвертой книге Дигест дважды переводит слово «captus» как «обманутый» (Ulp. 11 ad ed. D. 4,4,11,2 и 4), поэтому связывать его ошибку с незнанием элементарных вещей нельзя. Я не стану гадать, что послужило причиной допущенной ошибки, но могу признаться, что и меня этот текст сначала поставил в тупик, причем не своими грамматическими или стилистическими особенностями, а самим содержанием. Мне было непонятно, каким образом в Классический период один римский гражданин мог на законном основании стать рабом другого римского гражданина. Смысл фрагмента стал мне ясен, лишь, когда я вспомнил об указе императора Клавдия, разрешавшего на основании решения суда возвращать в рабство вольноотпущенника ${ }^{6}$, строившего козни против своего патрона, (Marc. 13 inst. D. 37,14,5 pr.; Suet. Claud. 25,1). Перевод такого фрагмента не кажется мне элементарной задачей.

С другой стороны, перевод в том же самом фрагменте словосочетания et ita saepissime est constitutum («и это весьма мудро установлено») действительно представляет собой элементарную ошибку. Однако она свидетельствует не о невежестве, а лишь о

${ }^{5}$ Жирным шрифтом выделен перевод Л.Л. Кофанова, курсивом - Д.О. Тузова.

${ }^{6}$ Таким образом речь в этом фрагменте идет не просто об обращении в рабство, как указано у Д.О. Тузова (с. 265 , прим. 7 ), а именно о возвращении в рабство. 
небрежности и усталости переводчика7. Когда долго работаешь, взгляд, как в таких случаях говорят, «замыливается» и начинаешь видеть в тексте то, чего там нет. Именно поэтому любой переводчик, даже самый опытный и квалифицированный, нуждается во внимательном и дотошном редакторе. Однако на первом этапе нашей работы Л.Л. Кофанов был единственным переводчиком, не имевшим редактора.

Следует отметить, что предложенные здесь Д.О. Тузовым переводы - правильны, но небезупречны. Когда в одной фразе мы встречаем слова «возможно» и «возможность» (с. 266), то это, выражаясь языком Д.О. Тузова, «режет слух», а словосочетание «и так весьма часто установлено» (с. 267) противоречит нормам русского языка. Разумеется, на основании этого нельзя заключить, что переводчик не знает элементарных вещей, но можно отметить, что его переводы нуждаются в редакционной правке не меньше, чем любые другие.

Приведем еще один пример элементарной, по мнению Д.О. Тузова, ошибки в переводе Л.Л. Кофанова - Ulp. 11 ad ed. D. 4,2,14,5:

...Arbitrium iudicis in restituenda re tale esse, ut eum quidem qui vim admisit iubeat restituere...

\begin{abstract}
...Решение судьи о восстановлении вещи в первоначальное положение таково, что (претор) приказывает вернуть вещь тому, кто применил силу...
\end{abstract}

Здесь Д.О. Тузова возмутила необъяснимая вставка Л.Л. Кофановым слова «претор», хотя «речь в данном фрагменте, казалось бы, недвусмысленно идет о судье». По мнению Д.О. Тузова,

7 Элементарные ошибки и неточности такого рода можно найти у любого переводчика, например, у И.С. Перетерского, в компетентности которого никто и никогда не сомневался (См. А.Л. Смышляев (рец.) - Дигесты Юстиниана. Избранные фрагменты, перевод и примечания И.С. Перетерского, Москва 1984, «ВДИ» 1986 № 1, с. 148 слл.). 
его оппонент просто не понимает разницы между тем и другим (с. 271). На самом деле сам Д.О. Тузов не учитывает в данном случае, что Юстиниановы компиляторы повсеместно заменяли слово praetor на слово iudex 8 , и именно, исходя из этого, Л.Л. Кофанов переводит данный фрагмент. Можно спорить о том, правилен или неправилен его перевод, но видеть в нем свидетельство элементарного невежества, нет никаких оснований.

Позднее Д.О. Тузов приводит еще один пример перевода, свидетельствующего о непонимании его оппонентом роли и функций претора - Ulp. 11 ad ed. D. 4,3,1,4:

...Famosa actio non temere debuit a praetore decerni, si sit civilis vel honoraria, qua possit experiri: usque adeo, ut et Pedius libro octavo scribit, etiam si interdictum sit quo quis experiri...

...Позорящий иск не должен устанавливаться претором наобум, если есть цивильный или преторский иски, с помощью которых он может вести судебное разбирательство. Это настолько верно, что, как пишет Педий в 8-й книге, если есть интердикт, посредством которого можно вести судебное разбирательство...

По мнению Д.О. Тузова, здесь его оппонент снова спутал судью с претором, решив, что в функции последнего входило «вести судебное разбирательство с помощью исков» и даже «посредством интердикта», «дабы не устанавливать наобум позорящий иск» (с. 274). Посмотрим, что получится, если продолжить оборванную на середине цитату:

...Famosa actio non temere debuit a praetore decerni, si sit civilis vel honoraria, qua possit

...Позорящий иск не должен устанавливаться претором наобум, если есть цивильный

${ }^{8}$ А. ВАКЕ, Переводить Дигестьл, Дигесть Юстиниана. VIII: Статьи и указатели, отв. ред. Л.Л. КоФАнов, Москва 2006, с. 35. 
experiri: usque adeo, ut et Pedius libro octavo scribit, etiam si interdictum sit quo quis experiri, vel exceptio qua se tueri possit, cessare hoc edictum. или преторский иски, с помощью которых он может вести судебное разбирательство. Это настолько верно, что, как пишет Педий в 8-й книге, если есть интердикт, посредством которого можно вести судебное разбирательство, или исковое возражение, с помощью которого (пострадавший от злого умысла) может защитить себя, то этот эдикт уступает им место.

Здесь мы видим, что речь идет о действиях в суде не претора, а «пострадавшего от злого умысла», который должен, разумеется, не «вести судебное разбирательство»", а судиться с помощью цивильного или преторского иска, либо интердикта, или же защищать себя с помощью искового возражения. Верный по существу перевод сформулирован небрежно и нуждается не в замене его другим переводом, а в минимальном редактировании: «...Позорящий иск не должен устанавливаться претором наобум, если есть цивильный или преторский иски, с помощью которых (пострадавший от злого умысла) может судиться. Это настолько верно, что, как пишет Педий в 8-й книге, если есть интердикт, посредством которого можно судиться, или исковое возражение, с помощью которого он может защитить себя, то этот эдикт не применяется».

Итак, там, где при определенном настрое и некоторой ловкости можно «обнаружить» дремучее невежество, на самом деле мы встречаем небрежность переводчика и отсутствие редакторской правки.

${ }^{9}$ В той же четвертой книге Л.Л. Кофанов правильно переводит actione... experiri и exceptione ... experiri как «судиться с помощью иска» или «судиться с помощью эксцепции» (Ulp. 11 ad ed. D. 4,2,9,3). Здесь опять элементарная ошибка, вызванная небрежностью. 
Следует отметить, что Д.О. Тузов способен «выявить» невежество оппонента и в тех случаях, когда тот не совершает промах и не проявляет беспечность. Так в переводе Л.Л. Кофановым выражения actio in rem scripta - «иск записывается как вещный» (Ulp. 11 ad ed. D. 4,2,9,8) он обнаруживает грубую ошибку, поскольку «речь шла не вещном иске, а об иске с абсолютным действием, в том смысле, что он мог быть направлен против любого получившего выгоду, а не только против принуждавшего». Эта ошибка связана, по мнению Д.О. Тузова с неверным - в данном конкретном случае - переводом термина res словом «вещь» (с. 268 сл.). К сожалению, он так и не сообщает заинтригованному читателю, каким же - в данном конкретном случае - словом надо перевести термин res. По моему мнению, если здесь и есть за что упрекнуть Л.Л. Кофанова, то разве что за некоторый буквализм. Может быть, лучше перевести это выражение словами «иск формулируется как вещный»? Зато в данном конкретном случае можно упрекнуть Д.О. Тузова, в том, что он, человек столь чувствительный к тонкостям правильной русской речи, не заметил очевидного: слово «как» указывает на подобие одного предмета другому, но никоим образом на их тождество. Если человек рычит на окружающих как лев, это вовсе не означает, что он и есть лев. Если иск «записывается как вещный», это значит, что он чем то похож на вещный, но на самом деле таковым не является.

Разбор перечисляемых Д.О. Тузовым неверных переводов можно продолжить, но это вряд ли поможет нам обнаружить что-либо новое в его технологии «выявления» грубых ошибок, якобы свидетельствующих о невежестве оппонента.

От разоблачения безграмотного переводчика Д.О. Тузов переходит к характеристике беспомощного редактора. Отметив полный разнобой при переводе выражений causae cognitio и causa cognita, он констатирует отсутствие контроля со стороны ответственного редактора за единообразием в переводе одних и тех же юридических терминов (с. 275-277). По его мнению, «отмеченных дефектов можно было легко избежать, обратившись к элементарному 
учебнику римского права или соответствующему справочному изданию» (с. 278).

Получается, что Л.Л. Кофанов не справился с задачей, решить которую под силу даже первокурснику - найти в любом элементарном учебнике или пособии общепринятый вариант перевода того или иного латинского правового выражения и проследить, чтобы все переводчики придерживались именно его. Возьмем какое-нибудь часто встречающееся правовое выражение и попробуем сами решить эту нехитрую задачу.

Вот, например, выражение operis novi nuntiatio, обозначающее понятие, которому посвящен отдельный титул Дигест Юстиниана (D. 39,1: DE OPERIS NOVI NUNTIATIONE). В переводе И.С. Перетерского этот титул называется: «О возражении против возведения нового сооружения» ${ }^{10}$. Автор известного юридического словаря Ф. Дыдынский переводит это выражение как «заявление о новой работе» ${ }^{11}$, а в энциклопедии М. Бартошека это «частный запрет нового строительства» ${ }^{12}$. В учебнике Д.В. Дождева даются два варианта перевода этого выражения: «заявление протеста на перестройку» и «запрещение новых работ» ${ }^{13}$. Другой вариант мы находим в русском переводе учебника Ч. Санфилиппо, изданном под редакцией Д.В. Дождева: «извещение о производимых вновь работах», а в указателе к нему - еще один: «извещение о производимых нежелательных работах» ${ }^{14}$. Таким образом, у пяти авторов элементарных пособий мы находим семь разных вариантов перевода одного и того же правового выражения.

${ }^{10}$ И.С. ПЕРЕТЕРСКИЙ, Дигесты Юстиниана. Очерки по истории составления и общая характеристика, Москва 1956, с. 120.

${ }^{11}$ Ф. Дыдынский, Латинско-русский словарь к источникам римского права: По изданию 1896 г. - Москва 1998, s.v. 'Nunciare' b., с. 370.

${ }^{12}$ М. БАртошек, Римское право: (Понятия, термины, определения), Москва 1989, c. 233.

${ }_{13}^{13}$ Д.В. Дождев, Римское частное право. Учебник для вузов, Москва 1996, c. 53,349 .

${ }^{14}$ Ч. САНФИлиппо, Курс римского права, Москва 2000, с. 183, 358. 
Поневоле задаешь себе вопрос: «Да так ли легко редактировать переводы памятников римского права, как это кажется некоторым начинающим романистам»? Ответ на этот вопрос можно найти у того же Д.В. Дождева. В предисловии к русскому переводу учебника Ч. Санфилиппо он отметил, что перевод терминов римского права оказался непростой задачей, при решении которой были приняты за основу русская традиция романистики, терминология, утвердившаяся в современном Гражданском кодексе России и современные языковые нормы. Свои нововведения в этой области он предложил рассматривать как рабочие гипотезы, материал для обсуждения. Задача разработки языка гражданского права остается, по его мнению, одной из самых актуальных, как в догматическом, так и в историческом аспекте развития этой дисциплины ${ }^{15}$. Таким образом, нормы перевода терминов римского права на русский язык пока еще только складываются и разрабатываются, поэтому разнобой в переводе латинских правовых терминов свидетельствует о незавершенности этого процесса, а не о беспомощности авторов элементарных пособий и редакторов переводов.

Найти общепринятый вариант перевода выражений causae cognitio и causa cognita еще сложнее, чем в случае с operis novi nuntiatio, ведь они обозначают, как отметил сам Д.О. Тузов, не одно, а два разных понятия: преторскую causae cognitio и cognitio extra ordinem, относившуюся к деятельности судьи и императорских чиновников (с. 277). По его мнению, переводчики и ответственный редактор допустили элементарную ошибку, спутав два этих понятия, поскольку они не понимают разницы между претором, с одной стороны, и судьей, а также императорскими чиновниками, с другой (с. 271 прим. 12, с. 277). Однако так ли легко провести четкую границу между causae cognitio преторов и императорских чиновников, как это представляется Д.О. Тузову?

Из «императорских чиновников» в связи с causae cognitio в Дигестах обычно упоминаются наместники провинций. Отправляя

${ }^{15}$ Д.В. ДожДЕВ, ПрЕДисловиЕ, [в:] Ч. САНФилиппо, Курс римского права. Москва 2000 , с. X. 
правосудие, они чаще всего обращались к cognitio extra ordinem, но в Классический период могли также, опираясь на свой эдикт, действовать в рамках формулярного процесса.

Преторы, наоборот, чаще всего отправляли правосудие в рамках формулярного процесса, но в Классический период некоторые из них, например, преторы по фидеикомиссам, решали дела только в порядке cognitio extra ordinem. Наконец, обычные традиционные преторы прибегали к causae cognitio не только в связи с формулярным процессом, но и при использовании особых или дополнительных процессуальных средств, основанных на их imperium и определявшихся «скорее властью, чем юрисдикцией». В этих случаях они сами проводили расследование дел. В классическом учебнике римского права, изданном под редакцией И.Б. Новицкого и И.С. Перетерского, такого рода расследования называют переходной ступенью между формулярным и когниционным производством ${ }^{16}$. А Д.В. Дождев, в учебнике которого наиболее полно представлены последние достижения современной науки, причисляет такие расследования к экстраординарным процессам $^{17}$. Основания для подобной классификации можно найти в Дигестах Юстиниана - Ulp. 49 ad ed. D. 38,15,2,1:

Dies bonorum possessionis utiles esse palam est: sed non sessionum numerabuntur, si modo ea sit bonorum possessio, quae de plano peti potuit. Quod si ea, quae causae cognitionem pro tribunali desiderat vel quae decretum exposcit, sessiones erunt nobis computandae, quibus sedit...
Ясно, что имеются полезные для вступления во владение (наследственным)имуществом дни, однако они считаются не по заседаниям суда, если владение (наследственным) имуществом таково, что его можно требовать без выслушивания в суде. Если же оно таково, что требует рассмотрения дела в

${ }^{16}$ Римское частное право, под ред. И.Б. НовиЦКОГо и И.С. ПЕРЕТЕРСКОГО, Москва 1948, с. 86.

17 Д.В. ДождЕв, Римское частное право. Учебник для вузов, Москва 1996, c. 107 . 
суде или нуждается в постановлении (претора), то нам следует считать заседания суда, в которых он заседает... (перевод Н.Ю. Чехонадской)

Таким образом, causae cognitio как претора, так и наместника провинции может представлять собой и исследование обстоятельств дела, и судебное разбирательство. И далеко не в каждом случае можно четко определить, какой вид causae cognitio имеется в виду. Поэтому переводить это правовое выражение и редактировать соответствующие переводы далеко не так просто, как это кажется Д.О. Тузову ${ }^{18}$.

На мой взгляд, грубые и элементарные ошибки, которые Д.О. Тузов «обнаруживает» у своего оппонента связаны с тем, что сам он не видит или не желает видеть реальные сложности и проблемы, связанные с переводами Дигест Юстиниана и редактированием этих переводов.

Остается только ответить на его упрек в том, что не были сделаны необходимые усилия для минимизации ошибок (с. 264). Я недостаточно компетентен, чтобы утверждать, будто в этом отношении не было никаких упущений. Но можно с полной уверенностью констатировать, что для минимизации ошибок делалось очень многое. С самого начала переводы, выполненные историками и филологами, проверялись и исправлялись научными редакторами из числа видных российских цивилистов. Со временем

${ }^{18}$ Кстати, определенный разнобой в передаче выражения causa cognita можно обнаружить и в современном переводе Дигест Юстиниана на немецкий язык, заслуженно считающемся образцовым (O. Behrends, R. KNÜTEL, B. KupISCH, H.H SeILER, 'Corpus Iuris Civilis', I-IV). Это выражение переводится там то как «после проверки обстоятельств дела (nach Prüfung der Sachlage)» - D. 1,18,7, то как «после предшествующего расследования (nach vorheriger Untersuchung)» D. 1,21,2,1, то как «после предварительного следствия (nach Voruntersuchung)» - D. 4,1,3. Странно, что ни один из многочисленных рецензентов не обвинил редакторов этого издания в некомпетентности. 
из лучших переводчиков выдвинулись редакторы переводов ${ }^{19}$. Таким образом, в последних томах русского издания Дигест переводы подвергались тройной проверке и правке: со стороны редактора перевода, научного редактора и ответственного редактора. Поэтому в этих томах досадных промахов и упущений значительно меньше, чем в первых ${ }^{20}$.

Следует отметить, что значительная часть неверных, с точки зрения Д.О. Тузова, исправлений была внесена в его переводы не ответственным редактором, а редактором перевода А.М. Сморчковым. Д.О. Тузов не упоминает об этом ни единым словом, чтобы не отвлекать читателя от своей главной мишени ${ }^{21}$.

Минимизации ошибок способствовала и подготовка новых переводчиков из числа молодых юристов, увлеченно осваивавших под руководством Л.Л. Кофанова римское право и юридическую латынь на организованных им курсах повышения квалификации и на семинаре по римскому праву. Одним из самых способных учеников оказался Д.О. Тузов. С помощью Л.Л. Кофанова он получил и прошел стажировку в крупнейших мировых центрах по изучению римского права: сначала в Варшаве, затем в Мессине и в Риме. По инициативе Л.Л. Кофанова, молодого перспектив-

${ }^{19}$ Причем переводы Л.Л. Кофанова так же подлежали их редактированию.

${ }^{20}$ Не случайно разгромная «критика» Д.О. Тузова почти целиком основывается на материалах первого из семи изданных томов переводов.

${ }^{21}$ Так получилось, что мои переводы из последних книг Дигест Юстиниана редактировал со свойственной ему обстоятельностью и дотошностью тот же А.М. Сморчков. Как и всякий автор, я стремился оспорить все его исправления, но каждый раз убеждался с чувством досады и негодования, что девять из каждых десяти совершенно справедливы. В тех случаях, когда я не соглашался со сделанной правкой, я оспаривал ее перед Л.Л. Кофановым. Случалось, что он не принимал мои аргументы и оставлял неверное, на мой взгляд, исправление. Случалось также, что он соглашался со мной, но, по недоразумению, это исправление оставалось в опубликованном тексте. Не скрою, что это ущемляло мое авторское самолюбие и вызывало досаду. Однако в силу присущей мне ограниченности я так и не додумался до того, чтобы излить эту досаду, написав злобный пасквиль на своего «обидчика» и опубликовав его сразу в нескольких журналах. 
ного романиста ввели в редколлегию журнала «Древнее право» и привлекли к переводу Дигест Юстиниана. Все ждали от него собственных работ по римскому праву. И, разумеется, первую из них он посвятил своему учителю. Что ж в этом мире, как известно, ни одно доброе дело не остается безнаказанным. 